\title{
The acquisition of tense morphology over time by English second language children with specific language impairment: Testing the cumulative effects hypothesis
}

\author{
JOHANNE PARADIS, RUITING JIA, and ANTTI ARPPE \\ University of Alberta
}

Received: June 16, 2016 Accepted for publication: October 21, 2016

\begin{abstract}
ADDRESS FOR CORRESPONDENCE
Johanne Paradis, Department of Linguistics, 4-57 Assiniboia Hall, University of Alberta, Edmonton, AB T6G2E7 Canada. E-mail: johanne.paradis@ualberta.ca
\end{abstract}

\begin{abstract}
The cumulative effects hypothesis $(\mathrm{CEH})$ claims that bilingual development would be a challenge for children with specific language impairment (SLI). To date, research on second language (L2) children with SLI has been limited mainly to their early years of L2 exposure; however, examining the long-term outcomes of L2 children with SLI is essential for testing the CEH. Accordingly, the present study examined production and grammaticality judgments of English tense morphology from matched groups of L2 children with SLI and L2 children with typical development (TD) for 3 years, from ages 8 to 10 with 4-6 years of exposure to English. This study found that the longitudinal acquisition profile of the L2 children with SLI and TD was similar to the acquisition profile reported for monolinguals with SLI and TD. Furthermore, L2-SLI children's accuracy with tense morphology was similar to that of their monolingual age peers with SLI at the end of the study, and exceeded that of younger monolingual peers with SLI whose age matched the L2 children's length of exposure to English. These findings are not consistent with the $\mathrm{CEH}$, but instead show that morphological acquisition parallel to monolinguals with SLI is possible for L2 children with SLI.
\end{abstract}

Children with specific language impairment (SLI) are late talkers whose language delay extends into their school years (Leonard, 2014). These children's protracted language development is not the consequence of other identifiable sensory, neurodevelopmental, or acquired disorders, for example, hearing loss, autism spectrum disorder, intellectual disability, or neurological trauma (Leonard, 2014). Studies have found that children with SLI show deficits in verbal memory and processing mechanisms compared to their peers with typical development (TD; Leonard et al., 2007; Miller, Kail, Leonard, \& Tomblin, 2001; Montgomery \& Windsor, 2007; for a review, see Leonard, 2014). Leonard and colleagues have hypothesized that memory and processing limitations could interfere with the

(C) Cambridge University Press 2017 0142-7164/17 
uptake of language input and, in so doing, be one proximal cause of the language learning difficulties exhibited by children with SLI (Leonard, 2014; Leonard et al., 2007; but see Oetting \& Hadley, 2009). Bilingual children, both simultaneous bilinguals from birth and sequential bilinguals/second language (L2) learners, experience more variation in their linguistic environment than monolingual children: they receive less input, on average, in each language than monolinguals; the relative amount of input in each language can be unequal and change over time; the diversity of interlocutors and contexts for use can differ between their languages; and in the case of sequential bilinguals, their learning of each language is staggered in age of onset (e.g., Grüter \& Paradis, 2014; Paradis \& Jia, 2016). Because bilingualism and SLI have consequences for children's experiences with linguistic input and for their potential uptake of that input, it has been hypothesized that dual language learning would be extraordinarily difficult for children with SLI (Crutchley, Conti-Ramsden, \& Botting, 1997; Jordaan, Shaw-Ridley, Serfontein, Orelowitz, \& Monaghan, 2001; Orgassa, 2009; Orgassa \& Weerman, 2008; Steenge, 2006; Verhoeven, Steenge, \& van Balkom, 2011; Verhoeven, Steenge, van Weerdenburg, \& van Balkom, 2011). Dual language learning could be especially challenging for children with SLI learning an L2. For example, an older age of acquisition onset could put L2 children with SLI at a disadvantage with respect to long-term attainment (Rice, 2010; Rothweiler, 2010). Furthermore, in the case of migrant L2 children, social factors such as lower socioeconomic status of the family and reduced input in a heritage language in a subtractive bilingual context could negatively impact language learning for children with SLI (Ebert, Pham, \& Kohnert, 2014; Jacobson, 2012; Morgan, Restrepo, \& Auza, 2013).

This notion that bilingualism might impose extra language learning difficulties on children with SLI can be referred to as the cumulative effects hypothesis (CEH; cf. Orgassa, 2009; Orgassa \& Weerman, 2008; Paradis, 2010a). "Cumulative" refers to the combined impact of internal language learning deficits and external complexities in linguistic input and experience brought on by bilingualism. The $\mathrm{CEH}$ predicts that bilingual children with SLI will lag behind both their monolingual peers with SLI and their bilingual peers with TD in language development generally. More specifically, the $\mathrm{CEH}$ predicts that bilingual children with SLI will likely never achieve abilities on a par with either group for domains of morphosyntax known to be clinical markers in SLI and/or difficult to master for L2 speakers. Alternatively to the $\mathrm{CEH}$, it has been argued that executive function advantages of bilingualism, interdependence between bilinguals' language systems, and more advanced learning mechanisms with older age of acquisition could mitigate the input/uptake challenges that bilingual children with SLI face (Blom \& Paradis, 2015; Ebert et al., 2014; Laloi, 2015; Paradis, 2010a, 2010b; Peets \& Bialystok, 2010).

There is mixed empirical support for the $\mathrm{CEH}$, but most studies of bilingual children with SLI have been focused on the early learning years, approximately 4-8 years old. Long-term outcomes in L2 acquisition are essential for testing the validity of the $\mathrm{CEH}$, because the $\mathrm{CEH}$ concerns the potential of children with SLI for dual language learning. Differences between monolinguals and bilinguals with SLI during the early stages of L2 acquisition could merely be a reflection of the L2 children not having had sufficient time to learn the L2. Accordingly, 
this longitudinal study examined the production and grammaticality judgments of tense morphology by English L2 children with and without SLI in the upper elementary school years. Tense morphology was chosen because it has been studied extensively in English monolinguals with and without SLI up to adolescence, and because it has been identified as a clinical marker of SLI in English in the early years (e.g., Oetting \& Hadley, 2009; Rice \& Wexler, 1996). We asked whether English L2 children with SLI and TD would show the same acquisition profile of tense morphology over time as their monolingual counterparts, and whether the L2 children with SLI would display similar accuracy with tense morphology to their monolingual peers with SLI after 4-6 years of exposure to English in school.

\section{COMPARING THE MORPHOSYNTAX OF BILINGUALS AND MONOLINGUALS WITH SLI}

The morphosyntactic abilities of young bilingual and monolingual children with SLI and their TD peers have been compared for English, French, Spanish, Dutch, and German. This research has focused on understanding if bilinguals and monolinguals with SLI who are the same age possess the same levels of morphosyntactic abilities. In addition, several studies have compared aspects of morphosyntax noted to be clinical markers in a language with control structures known to pose less difficulty for children with SLI in order to assess acquisition profiles of bilinguals and monolinguals.

Paradis, Crago, Genesee, and Rice (2003) and Paradis, Crago, and Genesee (2005-2006) studied 7-year-old French-English bilinguals with SLI in Canada and found that they had had equivalent difficulties to their monolingual peers with SLI in the acquisition of verb morphology in both languages and of direct object clitics in French. Children's relatively greater accuracy with control structures, object pronouns in English and articles in both languages, confirmed they had parallel acquisition profiles to monolinguals with SLI in each language. Paradis et al. concluded that bilingual exposure was not a source of additional delays for children with SLI. However, the children in these studies were simultaneous-from-birth bilinguals primarily from one-parent one-language households, and moreover, were learning two official, high-status languages. The social and learning circumstances could be quite different for sequential bilingual children with SLI from families with migrant backgrounds who speak a heritage language at home.

Orgassa and Weerman (2008) examined gender agreement in Dutch monolingual children with SLI and Dutch L2 children with and without SLI, aged 6 to 8 years. The L2 children were from Turkish-speaking families with a migration background, and they had an average of 5 years of exposure to Dutch. Orgassa and Weerman (2008) argued that their results revealed the L2 children with SLI to be significantly worse than both monolinguals with SLI and L2 children with TD, and thus, they displayed a "double delay" profile consistent with the CEH (Orgassa \& Weerman, 2008, p. 358; see Orgassa, 2009). Parallel findings supporting the CEH have emerged in larger scale studies of the morphological and syntactic abilities of Dutch L2 children with SLI (Steenge, 2006; Verhoeven, Steenge, \& van Balkom, 2011; Verhoeven, Steenge, van Weerdenbug, et al., 2011). These researchers studied bilingual and monolingual children with TD and SLI aged 6 to 9 years old. The 
bilingual children spoke Turkish, Arabic, or Berber as their first language (L1) and began systematic exposure to Dutch in school at age 4. The L2 children with SLI displayed consistently lower performance than both their monolingual peers with SLI and their bilingual peers with TD across numerous measures, prompting the researchers to consider them to be "additionally disadvantaged" (Verhoeven, Steenge, \& van Balkom, 2011, p. 1192.). Finally, Laloi (2015) studied Frenchspeaking bilingual and monolingual 7-year-old children with TD and with SLI in French. The L2 children had diverse L1 backgrounds and had 4-5 years of exposure to French. Children's abilities with the past tense and object clitics in French were examined. Laloi's (2015) statistical analyses did not yield evidence for the bilinguals with SLI performing worse than both the monolinguals with SLI and the bilinguals with TD; however, the raw scores clearly showed this pattern, and Laloi concluded that even if the CEH was not fully supported, there might have been some "additive effect" of bilingualism and SLI (Laloi, 2015, p. 117).

Other research on L2 children with a heritage L1 contrasts with this research on Dutch and French L2 children. For example, Rothweiler, Chilla, and Clahsen (2012) studied Turkish L1-German L2 children with SLI and monolingual German children with SLI who were 4.5 to 8 years old and started to learn German between the ages of 3 and 4 years. Their analyses of language samples from the children revealed that bilingual and monolingual children with SLI had the same grammatical profiles. Both had difficulties with subject-verb agreement morphology while showing relatively stronger syntactic skills, and moreover, the bilingual children did not have worse abilities than the monolingual children with subject-verb agreement. Gutiérrez-Clellen, Simon-Cereijido, and Wagner (2008) also found that Spanish-English bilingual and English monolingual children with SLI aged 4.5 to 6.5 had similar accuracy levels in their use of English verb morphology, and similar profiles compared to their peers with TD. Morgan et al. (2013) compared the Spanish morphosyntax of Spanish-English bilinguals with TD and SLI in the United States to that of monolingual Spanish speakers with TD and SLI in Mexico. Children were 5 to 6 years old. No significant differences were found in the Spanish performance of the bilinguals and monolinguals with SLI, and results showed that clinical markers were the same for bilinguals and monolinguals.

Most of the existing research comparing sequential bilinguals and monolinguals with SLI has included children from 4 to 8 years old. In some studies, the young age of the L2 children suggests that they had not been learning the L2 for much longer than 2 to 3 years (Gutiérrez-Clellen et al., 2008; Morgan et al., 2013). In other studies, the age of L2 onset indicates that some of the younger children in the sample would have only had about 2 to 3 years of L2 exposure at the time of testing (Orgassa, 2009; Orgassa \& Weerman, 2008; Rothweiler et al., 2012; Verhoeven, Steenge, \& van Balkom, 2011; Verhoeven, Steenge, van Weerdenburg, et al., 2011). Even if bilinguals and monolinguals with SLI show similar profiles and abilities in the L2 at the early learning stages, it is still possible that bilingual children with SLI might fall short of their monolingual peers in the longer term. Because the $\mathrm{CEH}$ is about the dual language learning capacity of children with SLI, it is critical to study older L2 children with longer L2 exposure to ascertain if the CEH is valid. The few studies including older bilingual children with long-term exposure are not 
conclusive. For example, the 9-year-old bilingual children with SLI in Verhoeven, Steenge, and van Balkom (2011) showed superior abilities to younger bilinguals with SLI, indicating ongoing growth. Nevertheless, the differences between them and the bilinguals with TD and the monolinguals with SLI were still substantial, consistent with the CEH. Jacobson (2012) and Jacobson and Livert (2010) found that growth in the Spanish and English morphosyntax of bilingual children with SLI and with TD in the upper elementary school grades was still ongoing; however, the absence of age-matched monolinguals with SLI as a comparison group limits what these studies can tell us about the CEH.

\section{ACQUISITION OF TENSE MORPHOLOGY BY ENGLISH MONOLINGUALS WITH SLI}

Young English-speaking children with SLI have selective deficits with tensemarking morphology in the early years, in addition to global language delay (Leonard, 2014; Oetting \& Hadley, 2009; Rice, 2003, 2004). Selective deficits means that their difficulties are worse than their overall language delay would indicate, and as such, tense morphology in English is a clinical marker of SLI. Tense morphemes that children with SLI find problematic are the following: third person singular-s, he walk-s; past tense regular, she walk-ed; past tense irregular, he ran; $\mathrm{BE}$ copula, she is happy; $\mathrm{BE}$ auxiliary, he is running; and DO auxiliary, Does she walk to school every day? (Bedore \& Leonard, 1998; Marchman, Wulfeck, \& Ellis Weismer, 1999; Rice \& Blossom, 2012; Rice \& Wexler, 1996; Rice, Wexler, \& Hershberger, 1998; Rice, Wexler, Marquis, \& Hershberger, 2000; Rice, Wexler, \& Redmond, 1999). As children with SLI proceed through elementary school, their global language abilities remain inferior to age expectations (Tomblin, Zhang, Buckwalter, \& O'Brien, 2003); however, the status of tense morphology as a clinical marker changes (Conti-Ramsden, Botting, \& Faragher, 2001; Oetting \& Hadley, 2009). In a longitudinal study of children with SLI, Rice and colleagues (Rice, 2004; Rice et al., 1998) found that the growth in accuracy with tense morphology in production of monolingual children with SLI reached close to TD levels by age 8; therefore, children with SLI narrowed, but did not entirely close, the gap with TD children their own age over time. TD children reached asymptote much earlier than children with SLI (around age 5), so the children with SLI showed very protracted development of tense (Rice, 2004; Rice et al., 1998). The narrowed gap in production by age 8 suggests that tense morphology would not discriminate between children with SLI and TD as well at this age than when children are younger. Conti-Ramsden et al. (2001) compared the diagnostic properties of linguistic clinical markers, such as verb inflection, with verbal memory tasks, such as nonword repetition, for 10-year-olds with SLI and concluded that at this age, the linguistic markers were not very effective identifiers.

Children with SLI not only have difficulties in producing tense morphology accurately but also show deficits in judging whether morphology is being used accurately (Rice et al., 1999). Regarding grammaticality judgments (GJ) over time, English monolingual children aged 6 to 8 show more protracted development than their TD peers, but children with SLI still performed significantly lower than their TD age peers at asymptote in development, suggesting that SLI-TD discrepancies 
in GJs would be ongoing past age 8 (Rice et al., 1999). Accordingly, Rice et al. conducted a study using a more challenging GJ task, omission of BE and DO in questions, with children with SLI 8-15 years old (Rice, Hoffman, \& Wexler, 2009). On this task, the older children with SLI had consistently lower performance than their TD peers, indicating tense continues to function as a clinical marker separating these groups when a more sensitive measure than production is used (Rice et al., 2009).

\section{TENSE MORPHOLOGY ACQUISITION BY ENGLISH L2 CHILDREN WITH SLI}

Young children with TD acquiring English as a L2 make errors with tense morphology, and it can take them years to catch up to their monolingual peers (Blom, Paradis, \& Sorenson Duncan, 2012; Chondrogianni \& Marinis, 2011; Jia \& Fuse, 2007; Marinis \& Chondrogianni, 2010; Paradis, Schneider, \& Sorenson Duncan, 2013; Paradis, Tulpar, \& Arppe, 2016). Nevertheless, English L2 children with SLI have exceptional difficulty with tense morphology in production compared to their TD L2 peers, indicating that differential abilities with tense morphology function as a clinical marker and can discriminate TD from SLI among L2 children, akin to monolinguals (Blom \& Paradis, 2013, 2015; Guitérrez-Clellen et al., 2008; Jacobson \& Livert, 2010; Jacobson \& Schwartz, 2005; Paradis, 2008, 2010a; Paradis et al., 2013). It remains to be shown whether English L2 children with SLI would display the same tense morphology profile over time for production and GJ that Rice and her colleagues have found for monolinguals, as discussed above (e.g., Rice et al., 1998, 1999, 2009).

Properties of the morphological constructions influence L2 children's accuracy with them. First, BE and inflectional tense morphemes appear to be acquired at different rates by L2 children. L2 children with TD show superior accuracy with $\mathrm{BE}$ forms, in production and in GJ, than with inflectional morphemes during the first 3 years of learning English (Paradis, 2008; Paradis \& Blom, 2016; Paradis, Rice, Crago, \& Marquis, 2008), and L2 children with SLI lag behind their L2 peers with TD more for inflectional tense morphology than for BE (Paradis, 2008, 2010a). This so-called precocious BE acquisition could be explained by the greater frequency of BE versus inflectional forms in the input (Paradis et al., 2008). Even though DO is an unbound morpheme like BE, there is some evidence that DO is more difficult to acquire than BE for L2 children with TD (Paradis et al., 2008, 2016) and for monolinguals with SLI (Rice et al., 2009), but how L2 children with SLI acquire DO is unknown. Second, the frequency of a word (verb + inflection) in the input influences accuracy in production of the inflection for L2 children, both with TD and with SLI, at the early stages of acquisition (Blom \& Paradis, 2013; Blom et al., 2012). The morphological accuracy of L2 children with TD continues to be sensitive to word frequency at later stages of L2 acquisition (Paradis et al., 2016), and thus, this could be the case for L2 children with SLI as well. Third, the target form of $\mathrm{BE}$ ( $i s=$ singular, are $=$ plural) influences the accuracy of L2 children with TD such that $i s$-for-are errors are more common than are-for- $i$ errors, possibly reflecting distributional frequency in the input (Paradis et al., 2008). Whether L2 children with SLI show a similar error pattern for BE 
(is $=$ singular, are $=$ plural $)$ is unknown, and whether either group shows a differential error pattern for DO forms (does $=$ singular, $d o=$ plural $)$ is also not known.

In sum, existing research has established tense morphology to be a clinical marker in English L2 children 4-8 years old, as it is in monolingual English children. In addition, L2 children's morphological acquisition patterns are influenced by properties of the morphological constructions during this period. However, very little is known about the morphological outcomes and patterns of L2 children with SLI at later stages of L2 acquisition and how they compare to their TD L2 age peers.

\section{THE PRESENT STUDY: RESEARCH QUESTIONS}

This study examined development of tense morphology over time in English L2 children with and without SLI in late elementary school. Children were followed from their fourth to sixth year of exposure to English. We examined the following set of English tense morphemes: third person singular $-s$ (3SG), past regular and irregular, BE (copula and auxiliary), and DO. We used both production and GJ tasks. We examined how L2-SLI children's acquisition of tense morphology compared with that of L2-TD children on the one hand, and with norms for monolinguals with SLI on the other hand. We reasoned that, if L2-SLI children displayed the same morphological acquisition profile compared to their TD-L2 peers (similar accuracy in production and differences for GJ, equal sensitivities to properties of the morphemes) and, furthermore, displayed similar morphological abilities as their monolingual peers with SLI, then the CEH would not be supported. By contrast, if L2-SLI children lagged behind both their TD-L2 peers and their monolingual peers with SLI at this late stage of L2 learning and if they showed some unique profile characteristics in their morphological abilities, this would constitute support for the $\mathrm{CEH}$. Specific research questions are follows:

1. Do L2-SLI children display similar or lower accuracy than L2-TD children with tense morphology over time? Are there differences in the group profiles for production versus GJ tasks?

2. Do properties of the morphological constructions such as morpheme form and frequency shape accuracy over time? Are L2-SLI children more or less sensitive to these properties than L2-TD children?

3. How do L2-SLI children compare to their monolingual age peers with SLI in their accuracy with tense morphology? How do L2-SLI children compare to younger monolingual children with SLI whose age matches the L2-SLI's children's length of exposure to English?

\section{METHOD}

\section{Participants}

Seven English L2 children with SLI and seven English L2 children with TD participated in this study. Children were identified from samples of children who 
Table 1. Participant characteristics

\begin{tabular}{llccc}
\hline \hline & Group & Round 1 & Round 2 & Round 3 \\
\hline Age & L2-TD & $93.71(6.75)$ & $106(6.59)$ & $118.3(7.11)$ \\
& L2-SLI & $92.14(8.55)$ & $105.7(8.78)$ & $117.7(8.78)$ \\
Age of acquisition onset & L2-TD & $46.29(6.29)$ & - & - \\
& L2-SLI & $47.14(10.91)$ & - & - \\
Length of exposure & L2-TD & $47.43(7.61)$ & $59.86(7.6)$ & $72(7.72)$ \\
Family members' use of & L2-SLI & $45(6.76)$ & $58.33(6.98)$ & $70.33(6.97)$ \\
English with child & L2-TD & $0.36(0.15)$ & $0.43(0.1)$ & $0.43(0.16)$ \\
Child's use of English & L2-SLI & $0.49(0.22)$ & $0.53(0.18)$ & $0.58(0.22)$ \\
with family members & L2-SLI & $0.55(0.27)$ & $0.64(0.3)$ & $0.73(0.2)$ \\
English richness & L2-TD & $0.71(0.31)$ & $0.75(0.31)$ & $0.71(0.37)$ \\
& L2-SLI & $0.67(0.1)$ & $0.68(0.08)$ & $0.68(0.1)$ \\
ALDeQ & L2-TD & $0.81(0.09)$ & $0.66(0.13)$ & $0.48(0.16)^{*}$ \\
TONI & L2-SLI & $0.41(0.14)^{* *}$ & - & - \\
& L2-TD & $111.6(17.7)$ & - & - \\
\hline \hline
\end{tabular}

Note: Age is chronological age in months. Length of exposure is months of exposure to English in daycare/preschool/school. Proportion of English use in the home, spoken to the child by family members and spoken by the child to family members, is calculated between 0 and 1.0, with 1.0 as only English being used/spoken. Richness of the English environment is calculated between 0 and 1.0, with 1.0 as the richest possible English environment. L2, Second language; TD, typically developing; SLI, specific language impairment; ALDeQ, Alberta Language Development Questionnaire (Paradis et al., 2010), a parent-report measure of first language developmental history and current abilities yielding a proportion score between 0 and 1.0, with higher scores signally more typical development; TONI, Test of Nonverbal Intelligence (Brown et al., 1997), yielding standard scores (mean $=100$, $1 S D$, range $=85-115$ ).

$* p<.05 . * * p<.01$. For Wilcoxon tests between L2-TD and L2-SLI.

participated in previous research (e.g., Blom \& Paradis, 2013, 2015; Paradis, 2011; Paradis, Emmerzael, \& Sorenson Duncan, 2010; Paradis et al., 2013) on the basis of how well they could be matched pairwise for age, amount of English exposure, and other variables (see Matching of TD and SLI Groups section). Approximately 30 families were contacted to see if they were willing to participate in a 3-year longitudinal study. About a third of the families no longer had the same contact information, and of those who we did succeed in contacting, the families of 14 children agreed to participate.

L2 children with TD and with SLI spoke a heritage L1 primarily or exclusively in the early years and were introduced to English as a L2 at age 4 years, 0 months $(4 ; 0)$, on average. All children had foreign-born parents who were also English L2 learners. All children were residing in Edmonton, an English-majority language city in Canada. Both the L2-TD and L2-SLI groups included a mix of children who were foreign born and Canadian born. See Matching of L2-TD and L2-SLI Groups section and Table 1, for more participant characteristics. 
L2 children with SLI were assessed by certified speech-language pathologists, and on the basis of this assessment were placed in special kindergarten programs for children with cognitive and language disabilities or received school-based speech-language pathology services in the case of children in Grades 1 or 2. Assessment tools and protocols varied, but the referring speech-language pathologists we worked with indicated that parent concern was present for each child. Although children were receiving services at the time when the earlier research was being conducted (when children were $5 ; 0-7 ; 0$ ), the children were not continuing to receive services when we conducted the present research; this is not uncommon for children identified as "mild-to-moderate" as opposed to "moderate-to-severe" in the Edmonton area, regardless of bilingualism.

\section{Materials and procedure}

Children were tested in their homes once a year, and parents were given questionnaires as interviews during the home visits. One parent questionnaire was used to obtain information on the child's current language environment, and the second questionnaire was focused on the child's L1 development; both questionnaires yielded background variables used for matching/contrasting groups. Children were given a test of abilities with verb morphology to yield our dependent variables as well as a nonverbal IQ screen, used as a background variable. What follows is a description of the questionnaires and tests.

The Alberta Language Environment Questionnaire (ALEQ). The ALEQ (Paradis, 2011; https://www.ualberta.ca/linguistics/cheslcentre/questionnaires) was administered to one parent, usually the mother, and with the aid of an interpreter if needed. This instrument includes questions on various topics, including age of onset of English acquisition, length of exposure to English in school, current language use by family members in the home, and the richness of the child's English environment. Information on language use in the home was gathered through questions such as "What language does the mother speak with the child?" or "What language does the child speak with the mother?" where answers were on 5-point rating scales from 0 (English never/mother tongue always) to 4 (English almost always/Mother tongue almost never). The proportion of family members' English use with the child and the child's use of English with family members was calculated from these rating scales (input-output quantity). Richness of the English environment (input quality) was determined by calculating the number of English-language activities the child engaged in (i.e., book-looking/reading, TV/computer watching, reciting songs/rhymes, extracurricular activities, and playing with English-speaking friends), and the frequency of these activities per week, to yield a proportional score from 0 to 1.0. We recognize that quantity and quality of English input cannot be entirely separated with this questionnaire, but we did not have research questions comparing quantity versus quality of input. Instead, we considered both variables to be environment factors potentially influencing children's L2 abilities, and we wanted to match the TD and SLI groups on these factors. Descriptives for the ALEQ variables are given for each round in Table 1. 
The Alberta Language Development Questionnaire (ALDeQ). The ALDeQ (Paradis et al., 2010; https://www.ualberta.ca/linguistics/cheslcentre/questionnaires) was also administered to the parents, but at Round 1 only. This is a parent questionnaire developed to obtain information on L2 children's L1 development in diverse contexts where it would be a challenge to examine the L1 directly. ALDeQ includes sections on early milestones, current L1 abilities, the child's behavior, and activity preferences and family history. Questions are answered with rating scales where higher scores are more consistent with typical language development and lower scores more consistent with impaired language development. ALDeQ scores contribute positively to discriminating between children with TD and children with SLI among L2 children (Paradis et al., 2013). ALDeQ scores were included in this study to reveal differences between the TD and SLI groups in language abilities at the outset beyond our dependent measures.

Test of Early Grammatical Impairment (TEGI). The TEGI (Rice \& Wexler, 2001) was given to the children, following the instructions in the examiner's manual. The TEGI includes production probes for 3SG, past regular and irregular, BE (copula and auxiliary), and DO. The TEGI also has GJ probes for correct use, incorrect use, or omission of verb morphemes.

For the 3SG probe, children were shown pictures of professionals engaged in work activities and given prompts, such as "Here is a teacher. Tell me what a teacher does." Expected answers included "A teacher writes on the board" or "A teacher teaches. "For the past tense probe, participants were shown pictures of children engaged in activities, followed by a picture showing the activity being completed, and given prompts, such as "Here the boy is raking. Now he is done. Tell me what he did." The expected answer would be "The boy/he raked ." Ten items elicited regular past tense $[-e d]$, and eight items elicited irregular past tense forms.

In the $\mathrm{BE} / \mathrm{DO}$ probe, children were prompted to ask questions or make statements using these morphemes. Items elicited BE copula, BE auxiliary, and DO auxiliary. In this task, the child had to direct his or her questions to a puppet about one or more stuffed animals, or make statements about the animals. Thus, third person singular and plural questions and statements were elicited using is/are and do/does. For instance, "I wonder if the bears are resting. Ask the puppet" was expected to prompt "Are the bears resting?" (BE auxiliary), and "I wonder about the Kitty. Ask the puppet if the Kitty is hungry" was expected to prompt "Is the Kitty hungry?" (BE copula).

In the TEGI GJ probe, the experimenter acted out a scenario with toys that includes two robots who children were told are just learning to speak English and do not say everything correctly. During the scenario, the children were asked to determine if the robots' statements were said correctly or incorrectly (right or not so good). The TEGI GJ probe examines children's ability to detect correct use or omission of verb morphemes (e.g., dropped marker, e.g., he jumps over there / * he jump over there or he is jumping over there / *he jumping over there; correct use or incorrect use of morphemes, e.g., bad agreement, e.g., he is jumping / *he am jumping; and omission of the progressive [-ing], e.g., dropped -ing, e.g., he is jumping / *he is jump). 
For the production probes, a proportion correct score for the morpheme targeted was calculated by dividing the child's correct responses by the total of scorable responses. Unscorable responses are those that were imitating the experimenter's prompt, off-topic, or included a completely different verb construction, for example, present progressive on the past tense probe. For the past tense probe, the TEGI scoring procedures include accepting overregularized past tense forms, for example, digged for $d u g$, as correct. For the purposes of this study, we scored overregularizations as incorrect when we separated regular from irregular past in the analyses, but used the TEGI procedure when comparing a child's score to the TEGI norms. For the GJ probe, following the examiner's manual, children's correct rejections, false alarms, misses, and hits were calculated and transformed into A-prime scores for dropped marker, bad agreement, and dropped -ing targets separately (Rice \& Wexler, 2001; Rice et al., 1999).

Test of Nonverbal Intelligence (TONI). The TONI (Brown, Sherbenou, \& Johnsen, 1997) is a nonverbal IQ test that is administered with minimal verbal instructions, and requires a pointing response. It consists of a series of shapes illustrating a pattern, and the child points to a shape in a separate array that would fit the pattern. The TONI was given at Round 1 only. By definition, children with SLI do not have intellectual disability (IQs at 70 or lower); however, they often have IQs in the low normal range, 85-100 (Leonard, 2014). We included this measure in the study to understand whether our group of children with SLI displayed this pattern, which they did (see Table 1).

\section{Matching of L2-TD and L2-SLI groups}

Pairwise matching for age, age of acquisition onset, length of exposure to English, and L1 background was undertaken at Round 1. Thus, each child with SLI had a TD match with the same L1 (or a typologically similar language as L1), chronological age, age of English acquisition onset, and months of exposure to English. Groups were balanced for L1s that mark tense grammatically and L1s that do not: each group had four children with tense-marking L1s (Farsi, Gujarati, Punjabi, and Urdu) and three children with non-tense-marking L1s (Cantonese and Vietnamese). Nonparametric Wilcoxon signed rank tests suggested that children were matched on age and length of exposure at Round 2 and 3 as well, since the differences were found to be nonsignificant. Group equivalency matching was examined, also using Wilcoxon tests, for language environment variables from the ALEQ: use of English by family members to the child, child's use of English with family members, and richness of the child's English environment. The results showed that children were matched at each round for all variables except English richness at Round 3 where L2-TD had significantly higher scores. Thus, for the most part, the L2-TD and L2-SLI groups were closely matched with respect to language environment. Finally, group differences were expected for ALDeQ and for TONI, following previous research with English L2 children with SLI for ALDeQ (Paradis et al., 2010, 2013) and previous research with monolingual children with SLI for nonverbal IQ (Leonard, 2014). Analyses with the Wilcoxon test revealed lower ALDeQ and TONI scores for the SLI group at Round 1. Descriptives for 


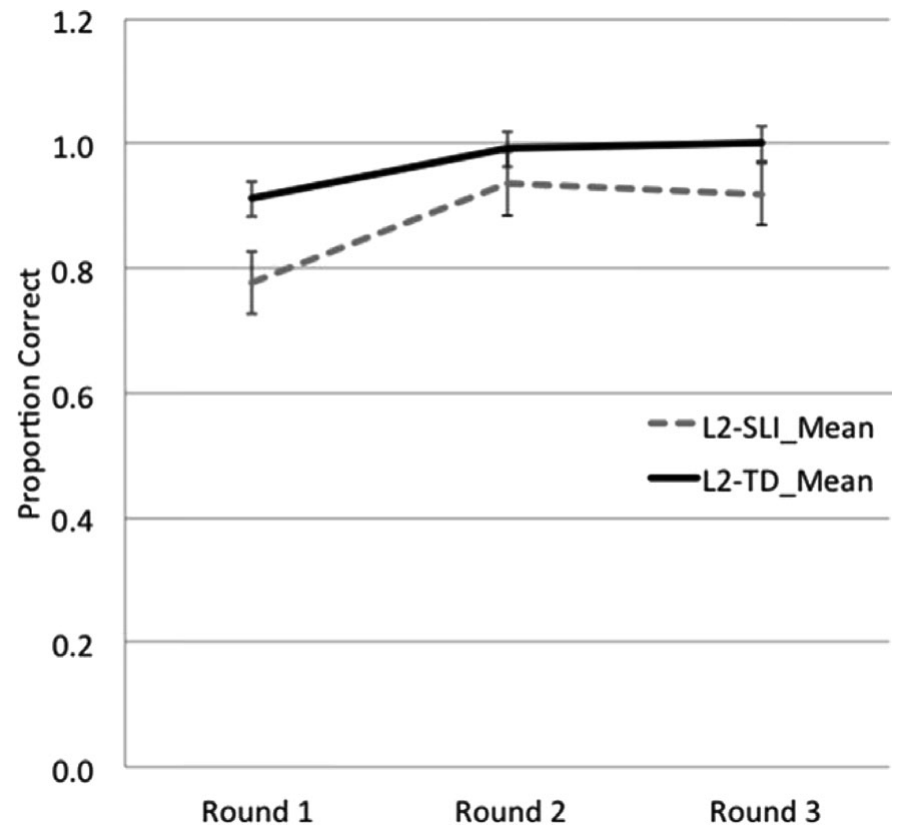

Figure 1. Mean scores across three rounds on the Test of Early Grammatical Impairment third person singular $-s$ probe for the second language-specific language impairment and the second language-typically developing groups. Rounds correspond to 4-6 years of exposure to English in school. Bars are standard errors.

participant characteristics for Rounds 1 to 3 are given in Table 1, with significant Wilcoxon comparisons noted.

\section{RESULTS}

\section{Modeling change over time and differences between L2-TD and L2-SLI}

Figures 1-7 display the proportion correct and a-prime scores for the L2-TD and L2-SLI groups across three rounds for each TEGI probe (past tense is divided into regular and irregular past). Bars are standard errors. We used linear mixed logistic regression modeling with the lme4 package (Bates, Maechler, Bolker, \& Walker, 2013) in the R statistical programming environment (R Core Team, 2013) in order to address research questions (1) and (2) above concerning differences between the L2-TD and L2-SLI group in their accuracy with tense morphology and the role of properties of the morphological constructions in shaping accuracy. Child, item, and round were random factors, with a random intercept for each item, and a random intercept and slope for each child dependent on round. Regarding test items, rather than aggregate proportion correct or a-prime scores for each probe, children's responses were coded as "TRUE" or "FALSE," indicating if the child gave a correct or incorrect answer to each item within each TEGI probe 


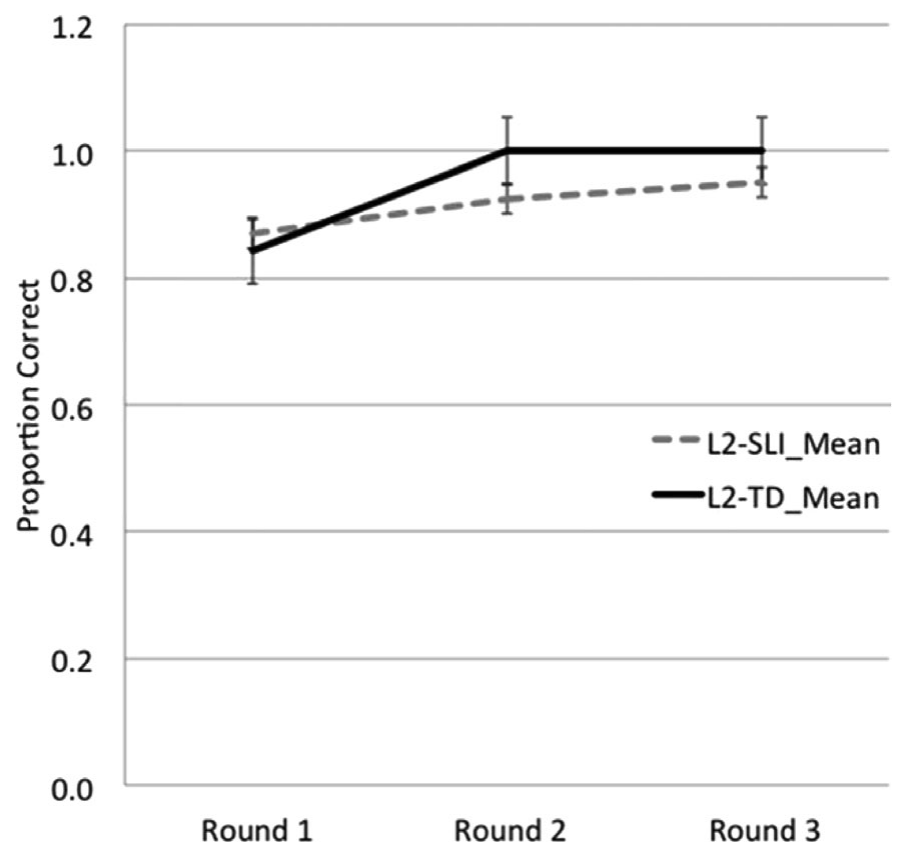

Figure 2. Mean scores across three rounds on the Test of Early Grammatical Impairment past-regular probe for the second language-specific language impairment and the second language-typically developing groups. Rounds correspond to 4-6 years of exposure to English in school. Bars are standard errors.

(for scorable items). Doing so meant that for all the probes combined, there were 2,166 data points (all three rounds) for the L2-SLI group and 2,394 data points for the L2-TD group. Child-level fixed factors were round (three ordinal levels: Round 1, Round 2, and Round 3) and group (two nonordinal levels: L2SLI and L2-TD), and item-level (language-level) factors varied by the probe. We included word frequency for inflectional morphemes (3SG, past regular, and past irregular), Target Form for BE ( $i s=$ singular, are = plural), DO (does = singular, $d o=$ plural) and for the GJ probes, BE or inflection. The word frequencies for the individual inflected verbs were derived from the Edmonton English Language Learners corpus, used in previous studies (see Blom \& Paradis, 2013; Blom et al., 2012; Paradis et al., 2016). Frequencies were log-transformed and entered into the data frame for each item (verb) on the TEGI probe. Because GJ accuracy was so stable and high for the GJ dropped -ing targets, no model was generated for dropped -ing.

The first step was to generate the best fitting, most parsimonious model (optimal model) for each TEGI probe. For the past tense probe, separate models were generated for regular and irregular verbs. The optimal model was determined through nested model comparisons where a fuller model with more fixed factors was compared to a reduced model with one fewer fixed factor to ascertain if the 


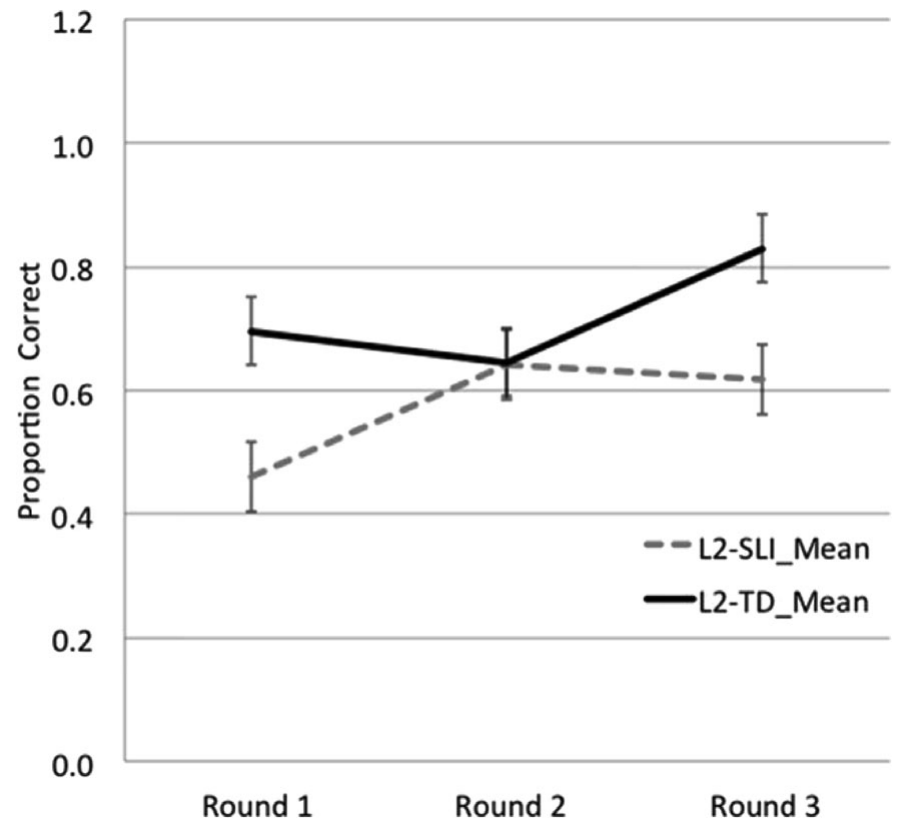

Figure 3. Mean scores across three rounds on the Test of Early Grammatical Impairment past-irregular probe for the second language-specific language impairment and the second language-typically developing groups. Rounds correspond to 4-6 years of exposure to English in school. Bars are standard errors.

difference in deviances between them produced a significant chi-square value at 1 degree of freedom $\left(\chi^{2}>3.84, p<.05\right)$. If so, the full model was chosen; if not, the reduced model was chosen as the optimal model. We then calculated the concordance index $C$ for the optimal model to assess whether this optimal model was a good fit. $C$ ranges from 0.50 to 1.0 , and models of 0.80 or higher are considered to be good-fitting models (Chatterji \& Hadi, 2006).

Production: $3 S$ G. For this probe, 377 data points were analyzed. A full model was first fitted model with group (L2-TD or L2-SLI) and round $(1,2,3)$ as child-level fixed factors and word frequency as an item-level fixed factor. The optimal model included just round as a significant fixed factor and no significant interactions between round and group or round and word frequency. This model has a $\mathrm{C}$ value of 0.91 , indicating a good fit, and model details are in Table 2. The optimal model shows Round 2 was significantly different from Round 1, but Round 3 was not significantly different from Round 2 . We followed up on the significant round factor with an analysis of the slope differences for the L2-TD and L2-SLI groups separately. For the L2-SLI group, a significant change in slopes was found from Round 1 to Round $2(z=2.382, p=.0178)$, but not from Round 2 to Round 3. For the L2-TD group, there was no significant change in slope across the three rounds. Thus, the main effect for round was primarily due to the L2-SLI group. 


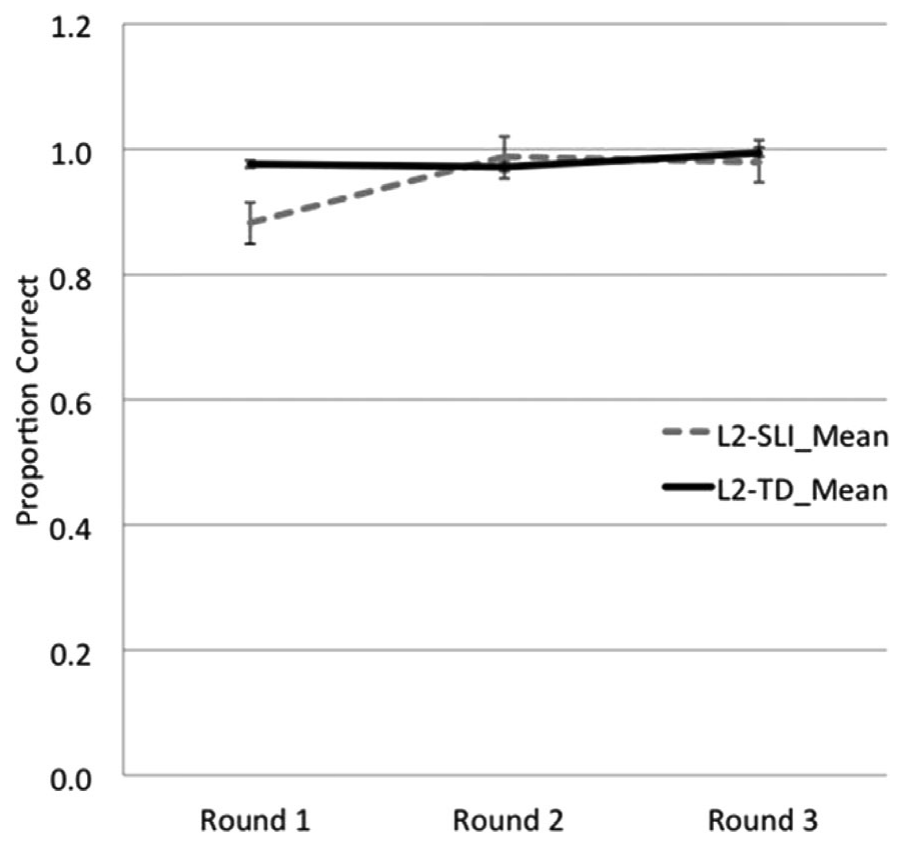

Figure 4. Mean scores across three rounds on the Test of Early Grammatical Impairment BE probe for the second language-specific language impairment and the second language-typically developing groups. Rounds correspond to 4-6 years of exposure to English in school. Bars are standard errors.

Production: Past regular. A full model fitted to 329 data points with round, group, and word frequency as fixed factors was generated first. Subsequent analyses determined that the optimal model included only round as a significant factor, with a $C$ value of 0.95 , and the details can be found in Table 3 . The optimal model shows Round 2 was significantly different from Round 1, and Round 3 was not significantly different from Round 2. Follow-up analyses for the SLI and TD children separately showed that neither group had significant changes in performance over time; thus, the significant effect for round emerged when the children's data were combined.

Production: Past irregular. We first fitted a full model with round, group, and word form frequency as fixed factors for 279 observations. We then examined interaction effects and found a significant interaction between round and group. The optimal model details are in Table 4 , and the $C$ value is 0.89 . The main effects and interaction effects for L2-TD and L2-SLI and round indicate that the two groups differed at Rounds 1 to 2 and at Rounds 2 to 3, with L2-TD showing higher accuracy with irregular verbs than L2-SLI at these rounds. Additional analyses examining change across rounds for L2-SLI and L2-TD separately showed the following: the L2-SLI group had significant change from Round 1 to $2(z=2.726$, 


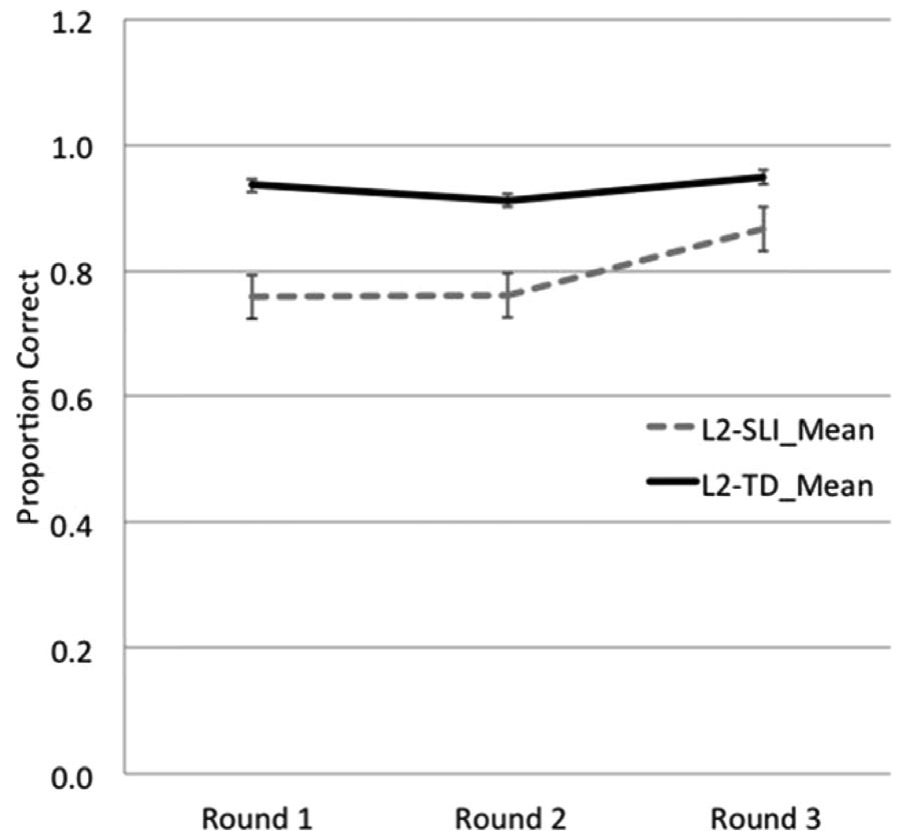

Figure 5. Mean scores across three rounds on the Test of Early Grammatical Impairment DO probe for the second language-specific language impairment and the second language-typically developing groups. Rounds correspond to 4-6 years of exposure to English in school. Bars are standard errors.

$p=.00641$ ), but not from Round 2 to 3 . The L2-TD group had the opposite pattern with no change from Round 1 to 2, but significant change from Round 2 to 3 $(z=2.832, p=.00463)$. This difference in developmental trajectories resulted in no between-group differences in accuracy at Round 2. This pattern is visible in Figure 3. Finally, children in both groups were more accurate in producing past irregular forms for verbs that appear more frequently in the input.

Production: BE. The first full model included round, group, and target form (is, are) modeling 932 data points. The optimal model included round as the only significant fixed factor. Model details are in Table 5; C value is 0.96 . There was a trend toward change in slope from Round 1 to Round 2; a significant difference emerged between Round 2 and 3. Follow-up, separate slope analyses for L2-TD and L2-SLI revealed that the L2-SLI group showed significant gains from Round 1 to 2 ( $z=2.585, p=.00973)$, but not from Round 2 to 3 . The L2-TD children's performance did not show significant change across the three rounds. Thus, the trend from Round 1 to 2 was mainly due to the increase in accuracy of the L2-SLI group, and the change from Round 2 to 3 was due to the combined scores of both groups. 


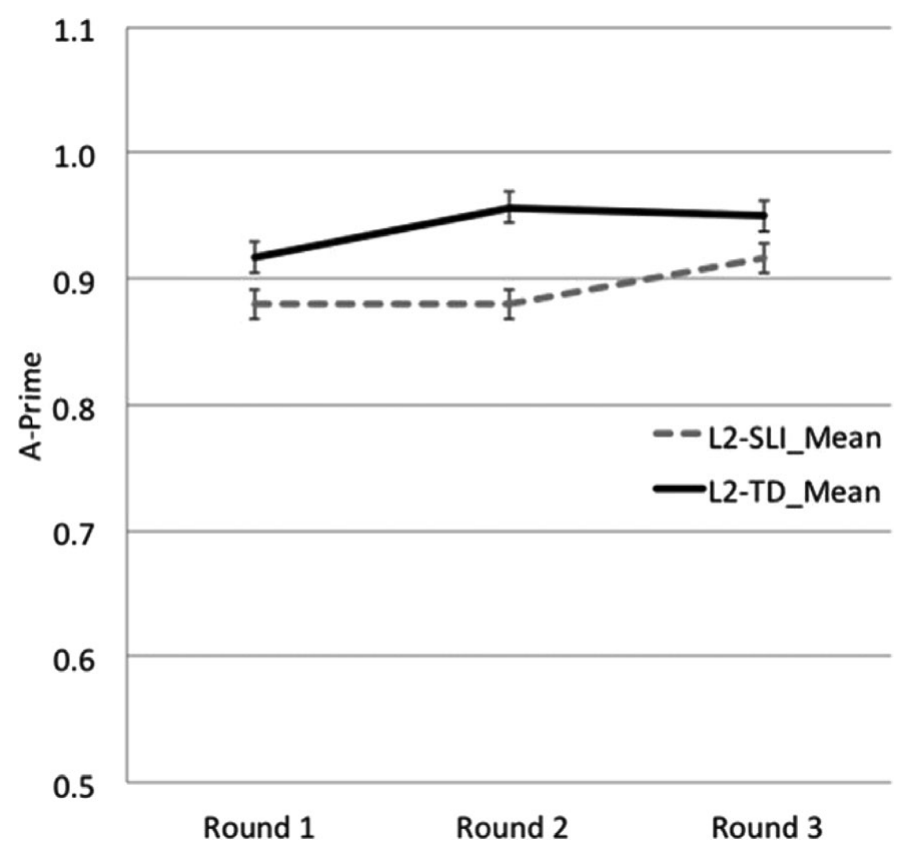

Figure 6. Mean scores across three rounds on the Test of Early Grammatical Impairment grammaticality judgment-dropped marker probe for the second language-specific language impairment and the second language-typically developing groups. Rounds correspond to 4-6 years of exposure to English in school. Bars are standard errors.

Production DO. The DO probe yielded 442 data points; and we fitted a full model with round, group, and target form (does, do). The optimal model had a $C$ value of 0.96 and included round, group, target form, and an interaction between target form and group, although not all of these factors were significant (Table 6). There was significant change between Round 2 and Round 3, but not between Round 1 and 2 . The children were significantly more accurate with does than do targets, and the interaction trend indicated that his differential accuracy was more prominent for the L2-SLI than the L2-TD children. Regarding separate slope analyses, no significant effects were found, indicating that changes from Round 2 to 3 were due to the combined scores.

GJ: Dropped marker. For this probe, 682 data points were modeled with round, group, and target form (BE, inflection). The optimal model included just group and target form, but not round, with a $C$ value of 0.90 (Table 7). Thus, there were no significant changes in scores over time, and this was confirmed by nonsignificant separate slope analyses for the two groups. The significant effect of group indicated that the L2-SLI children had consistently lower performance on this probe than the L2-TD children. Both groups of children had lower scores for lexical inflection targets than for targets with BE. 


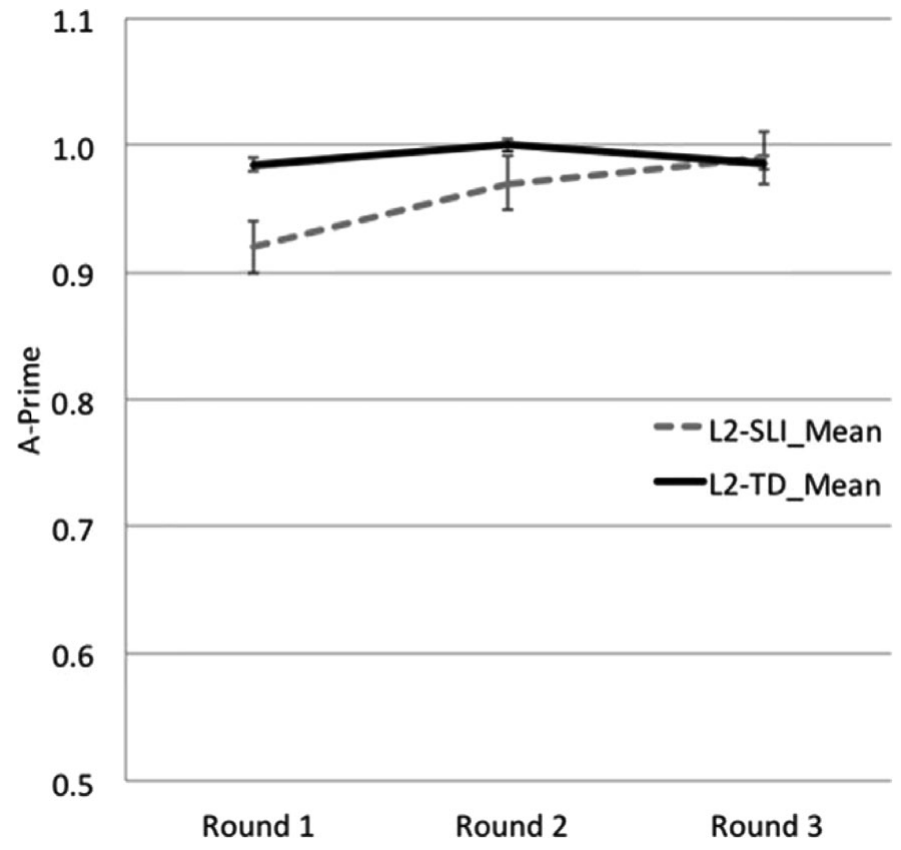

Figure 7. Mean scores across three rounds on the Test of Early Grammatical Impairment grammaticality judgment-bad agreement probe for the second language-specific language impairment and the second language-typically developing groups. Rounds correspond to 4-6 years of exposure to English in school. Bars are standard errors.

Table 2. Optimal model for $3 S G$ production probe

\begin{tabular}{lrrrl}
\hline \hline & Estimate & $S E$ & \multicolumn{1}{c}{$z$} & \multicolumn{1}{c}{$\operatorname{Pr}(>|z|)$} \\
\hline Intercept & 4.2252 & 0.8214 & 5.144 & $2.69 \mathrm{e}-07 * * *$ \\
Round 1 & -1.3646 & 0.5763 & -2.368 & $0.0179 *$ \\
Round 3 & 0.2299 & 0.6622 & 0.347 & 0.7285 \\
\hline \hline
\end{tabular}

Note: Round 2 was taken as the reference level, so Round 1 indicates a significant difference between Round 1 and Round 2, and Round 3 indicates a significant difference between Round 2 and Round 3.

$* p<.05 . * * * p<.001$.

GJ: Bad agreement. This probe yielded 739 observation points that were fitted with a full model, including round, group, and target form (BE or inflection). The optimal model in Table 8 includes round and group as significant fixed effects, with a $C$ value of 0.90 . There were significant changes in children's performance from Round 1 to Round 2, but not from Round 2 to Round 3. L2 children with SLI had significantly lower scores than L2 children with TD. Separate slope analyses showed that the L2-SLI group showed a trend toward an increase in scores from 
Table 3. Optimal model for past regular production probe

\begin{tabular}{lrcrl}
\hline \hline & Estimate & $S E$ & $z$ & \multicolumn{1}{c}{$\operatorname{Pr}(>|z|)$} \\
\hline Intercept & 5.0148 & 1.1524 & 4.352 & $1.35 \mathrm{e}-05^{* * *}$ \\
Round 1 & -1.7279 & 0.7278 & -2.374 & $0.0176^{*}$ \\
Round 3 & 0.5429 & 0.8334 & 0.651 & 0.5147 \\
\hline \hline
\end{tabular}

Note: Round 2 was taken as the reference level, so Round 1 indicates a significant difference between Round 1 and Round 2, and Round 3 indicates a significant difference between Round 2 and Round 3. $* p<.05 . * * * p<.001$.

Table 4. Optimal model for past irregular production probe

\begin{tabular}{lrcrl}
\hline \hline & Estimate & $S E$ & $z$ & \multicolumn{1}{c}{$\operatorname{Pr}(>|z|)$} \\
\hline Intercept & -1.03671 & 0.72419 & -1.432 & 0.15228 \\
Round 1 & -2.13635 & 0.66824 & -3.197 & $0.00139^{* *}$ \\
Round 3 & -0.05998 & 0.60719 & -0.099 & 0.92131 \\
Group & 0.01970 & 0.79932 & 0.025 & 0.98033 \\
Word frequency & 0.82404 & 0.16720 & 4.928 & $8.29 \mathrm{e}-07^{* * *}$ \\
Round 1 × Group & 2.60999 & 0.87144 & 2.995 & $0.00274^{* *}$ \\
Round 3 × Group & 1.92326 & 0.88000 & 2.186 & $0.02885^{*}$ \\
\hline \hline
\end{tabular}

Note: Group is second language typically developing or second language specific language impairment. Round 2 was taken as the reference level, so Round 1 indicates a significant difference between Rounds 1 and 2, and Round 3 indicates a significant difference between Rounds 2 and 3. Word frequency is log transformed.

$* p<.05 . * * p<.01 . * * * p<.001$.

Table 5. Optimal model for BE production probe

\begin{tabular}{lrrrl}
\hline \hline & Estimate & $S E$ & \multicolumn{1}{c}{$z$} & \multicolumn{1}{c}{$\operatorname{Pr}(>|z|)$} \\
\hline Intercept & 6.180 & 1.292 & 4.784 & $1.72 \mathrm{e}-06^{* * *}$ \\
Round 1 & -1.421 & 0.759 & -1.873 & $0.0611 \dagger$ \\
Round 3 & 2.197 & 1.107 & 1.985 & $0.0471^{*}$ \\
\hline \hline
\end{tabular}

Note: Round 2 was taken as the reference level, so Round 2 indicates a significant difference between Rounds 1 and 2, and Round 3 indicates a significant difference between Round 2 and 3 .

$\dagger p<0.1 . * p<.05 . * * * p<.001$.

Round 1 to 2 ( $z=1.745, p=.0809$ ), but no change from Round 2 to 3 . The L2-TD group had constant scores across three rounds. Thus, changes in round as a main effect were likely due to the L2-SLI group. 
Table 6. Optimal model for DO production probe

\begin{tabular}{lrcrl}
\hline \hline & Estimate & $S E$ & $z$ & $\operatorname{Pr}(>|z|)$ \\
\hline Intercept & 1.3784 & 1.2225 & 1.128 & 0.25950 \\
Round 1 & -0.2538 & 0.5814 & -0.436 & 0.66248 \\
Round 3 & 1.3892 & 0.6942 & 2.001 & $0.04536^{*}$ \\
Group & 2.5380 & 1.7041 & 1.489 & 0.13639 \\
Target form & 1.9119 & 0.6575 & 2.908 & $0.00364^{* *}$ \\
Group $\times$ Target Form & 2.1288 & 1.2569 & 1.694 & $0.09033 \dagger$ \\
\hline \hline
\end{tabular}

Note: Round 2 was taken as the reference level, so Round 2 indicates a significant difference between Rounds 1 and 2, and Round 3 indicates a significant difference between Round 2 and 3. Group = L2-TD or L2-SLI. Target Form $=$ do or does. $\dagger p<0.1 . * p<.05 . * * * p<.001$.

Table 7. Optimal model for dropped marker grammaticality judgment probe

\begin{tabular}{lrcrl}
\hline \hline & Estimate & $S E$ & $z$ & \multicolumn{1}{c}{$\operatorname{Pr}(>|z|)$} \\
\hline Intercept & 3.2106 & 0.7777 & 4.128 & $3.66 \mathrm{e}-05^{* * *}$ \\
Group & 1.8384 & 0.9094 & 2.021 & $0.04323^{*}$ \\
Target form & -1.6981 & 0.6136 & -2.768 & $0.00565^{* *}$ \\
\hline \hline
\end{tabular}

Note: Group is second language typically developing or second language specific language impairment. Target form is $\mathrm{BE}$ or inflection.

$* p<.05 . * * p<.01 . * * * p<.001$.

\section{English L2 with SLI compared to monolinguals with SLI}

In order to address research question (3) above, the L2-SLI groups' mean scores on each TEGI probe were first compared with the mean scores for different age groups from the TEGI norming sample (TEGI examiner's manual; Rice \& Wexler, 2001, p. 65). We conducted one-sample, nonparametric tests for two means with the Wilcoxon signed rank test, comparing the L2-SLI with age-matched monolingual peers with SLI. Because the L2-SLI children were aged 7;8 and 8;10 at Rounds 1 and 2, they were compared to the mean scores for the monolingual 7 - and 8 -year-old groups $(7 ; 0-7 ; 11$ and $8 ; 0-8 ; 11)$. All comparisons for each probe and Rounds 1 and 2 revealed nonsignificant differences between the L2-SLI and the monolinguals with SLI the same age (see Table 9). No comparisons were made for Round 3, because the L2-SLI children were older than the TEGI norming sample. We next compared the scores of the L2-SLI group to younger monolingual children with SLI whose ages matched the L2-SLI children's length of exposure to English. The rationale for this was that the younger monolinguals' age would be equivalent to their exposure to English, so this comparison was aimed at understanding performance levels between the groups for a fixed length of exposure to English, 
Table 8. Optimal model for bad agreement grammaticality judgment probe

\begin{tabular}{lrrrl}
\hline \hline & Estimate & $S E$ & \multicolumn{1}{c}{$z$} & \multicolumn{1}{c}{$\operatorname{Pr}(>|z|)$} \\
\hline Intercept & 3.7279 & 0.7624 & 4.889 & $1.01 \mathrm{e}-06^{* * *}$ \\
Round 1 & -1.3718 & 0.5969 & -2.298 & $0.0216^{*}$ \\
Round 3 & -0.7562 & 0.6389 & -1.184 & 0.2366 \\
Group & 1.9384 & 0.8142 & 2.381 & $0.0173^{*}$ \\
\hline \hline
\end{tabular}

Note: Round 2 was taken as the reference level, so Round 2 indicates a significant difference between Rounds 1 and 2 , and Round 3 indicates a significant difference between Round 2 and 3. Group is second language typically developing or second language specific language impairment. $* p<.05 . * * * p<.001$.

regardless of age. The results in Table 9 show that for each TEGI probe at each Round, the L2-SLI group had significantly higher TEGI scores than their younger monolingual peers with SLI.

\section{DISCUSSION}

The objective of this study was to examine the acquisition of tense morphology in English L2 children with SLI, as compared to their TD L2 peers and monolingual peers with SLI, in order to test the CEH. We chose to focus on abilities with tense morphology because this is a clinical marker in English SLI, for both bilingual and monolingual speakers, and because there is prior research on the acquisition profiles of older monolingual children with TD and with SLI for tense morphology. To date, there has been very limited research on older L2/bilingual children with SLI, and yet understanding long-term outcomes in dual language learning is vital to understanding if the CEH is valid or not. This study aimed to fill this gap.

Two groups of English L2 children were included: one group of children with TD and another group with SLI. Groups were matched for L1 background, age, age of L2 onset, amount of English exposure in school, and quality and quantity of English input outside school. Children were followed longitudinally for 3 years, from 8 to 10 years old. We asked whether the L2-TD and L2-SLI children showed the same tense acquisition profiles as their monolingual peers in the longer term. This included examining differences between the L2-TD and L2-SLI groups over time, for production and GJ tasks from the TEGI. We also asked whether L2-TD and L2-SLI would show similar sensitivities to the properties of the morphological constructions in their acquisition, similar to their L2 peers at earlier stages of L2 learning. Finally, we asked whether the L2-SLI children would show abilities with tense morphology on a par with their monolingual peers with SLI from the TEGI norming sample.

Regarding comparisons between the L2-SLI and L2-TD groups for the TEGI probes, we found the following: for the production probes, L2-SLI children had lower accuracy for irregular past tense only, and were equivalent to the L2-TD 
Table 9. Age and exposure for age comparison between monolinguals with SLI and L2 children with SLI for mean scores on TEGI probes

\begin{tabular}{lccccc}
\hline \hline & \multicolumn{2}{c}{ MONO-SLI } & & \multicolumn{2}{c}{$p$} \\
\cline { 2 - 3 } \cline { 5 - 6 } TEGI Probe & Mean-Age $^{a}$ & Mean-Exp & L2-SLI Mean & Age-Age & Age-Exp \\
\hline 3SG R1 & $0.69(0.34)$ & $0.26(0.35)$ & $0.83(0.17)$ & .95 & $.00005^{* * * *}$ \\
3SG R2 & $0.73(0.35)$ & $0.39(0.34)$ & $0.97(0.08)$ & .99 & $.00001^{* * *}$ \\
3SG R3 & NA & $0.47(0.35)$ & $0.95(0.08)$ & .99 & $.00002^{* * *}$ \\
PAST R1 & $0.76(0.23)$ & $0.30(0.25)$ & $0.78(0.30)$ & .82 & $.00200^{* * *}$ \\
PAST R2 & $0.78(0.24)$ & $0.48(0.27)$ & $0.94(0.07)$ & .99 & $.00001^{* * *}$ \\
PAST R3 & NA & $0.49(0.30)$ & $0.92(0.08)$ & .98 & $.00003^{* * *}$ \\
BE R1 & $0.79(0.23)$ & $0.40(0.35)$ & $0.90(0.17)$ & .89 & $.00001^{* * *}$ \\
BE R2 & $0.78(0.22)$ & $0.57(0.34)$ & $0.99(0.02)$ & .99 & $.00000^{* * *}$ \\
BE R3 & NA & $0.60(0.25)$ & $0.98(0.03)$ & .99 & $.00000^{* * *}$ \\
DO R1 & $0.67(0.31)$ & $0.09(0.24)$ & $0.78(0.25)$ & .86 & $.00010^{* * *}$ \\
DO R2 & $0.67(0.27)$ & $0.20(0.31)$ & $0.76(0.22)$ & .89 & $.00080^{* * *}$ \\
DO R3 & NA & $0.30(0.28)$ & $0.87(0.21)$ & .95 & $.00060^{* * *}$ \\
GJ-DM R1 & $0.76(0.20)$ & $0.43(0.30)$ & $0.84(0.19)$ & .67 & $.00006^{* * *}$ \\
GJ-DM R2 & $0.83(0.16)$ & $0.43(0.29)$ & $0.90(0.14)$ & .8 & $.00025^{* * *}$ \\
GJ-DM R3 & NA & $0.58(0.26)$ & $0.87(0.14)$ & .78 & $.00220^{* *}$ \\
GJ-BA R1 & $0.82(0.20)$ & $0.46(0.35)$ & $0.87(0.19)$ & .6 & $.00050^{* * *}$ \\
GJ-BA R2 & $0.88(0.15)$ & $0.50(0.34)$ & $0.98(0.06)$ & .99 & $.00000^{* * *}$ \\
GJ-BA R3 & NA & $0.65(0.29)$ & $0.96(0.06)$ & .98 & $.00005^{* * *}$ \\
\hline \hline
\end{tabular}

Note: The NAs in the second column were entered because the TEGI norming sample data does not go beyond age 8 years, 11 months $(8 ; 11)$, and at Round 3 the L2-SLI sample had a mean age of 9;10. SLI, Specific language impairment; L2, second language; TEGI, Test of Early Grammatical Impairment; MONO, monolingual children; R1-R3, Rounds 1-3. ${ }^{a}$ Monolingual children with SLI from TEGI norming sample matched for mean age with L2-SLI group: Age-Age. Scores are from the TEGI Examiner's Manual (Rice \& Wexler, 2001, p. 65).

${ }^{b}$ Younger monolingual children with SLI from TEGI norming sample whose ages were matched with L2-SLI group's length of exposure to English: Age-Exp. Scores are from the TEGI Examiner's Manual (Rice \& Wexler, 2001, p. 65).

$* * p<.01 . * * * p<.001$.

children for the other probes. By contrast, for the GJ probes, L2-SLI children showed lower accuracy than the L2-TD children. Regarding change over time, when grouped together, the L2 children showed an increase in accuracy, or a trend toward an increase, for all the probes except for GJ: Dropped marker. However, analyses of the slopes for the groups separately revealed that most of the change over time was due to the L2-SLI group from Rounds 1 to 2. This indicates that the L2-SLI children were still in the process of acquiring tense morphology during this time period while their TD peers showed more stable performance across the time period. Regarding morpheme-level factors, both groups of children were sensitive to word frequency for past irregular targets, to singular versus plural for DO (SLI were more sensitive here), and to whether the target was a lexical verb inflection or a BE form on the dropped marker probe. These patterns are consistent 
with earlier stages of L2 acquisition (Blom \& Paradis 2013; Paradis, 2008; Paradis et al., 2008), and crucially, no differences emerged between L2-SLI and L2-TD.

Following the comparison between the $\mathrm{L} 2$ groups, we also compared the performance of the L2-SLI children to monolinguals with SLI from the TEGI norming sample. For both Rounds 1 and 2, the L2-SLI children's mean scores on each probe were not significantly different from the mean scores of their monolingual age peers with SLI. Furthermore, the L2-SLI children showed vastly superior accuracy with tense morphology on every probe when compared with younger monolingual children with SLI whose age matched the English exposure time of the L2 children. We explore what this latter finding might mean in the next section.

Overall, the longitudinal tense acquisition profile of L2 children with SLI parallels what has been found for monolinguals (Rice et al., 1998, 1999, 2000, 2009). The asymmetry in between-group differences in production and GJs aligns with the findings of Rice et al. The parallels with monolinguals are evident also in the developmental trajectories. As with monolinguals, the L2-SLI children in this study showed more growth in their abilities with tense than children with TD, signaling they had a more protracted acquisition trajectory than the L2-TD group. Finally, while monolingual children with SLI grow closer to their TD peers for marking morphology in general over time, akin to our study, they still show persistent difficulties in using the correct form of irregular past tense verbs (Rice et al., 2000).

One difference between our findings and those for monolinguals is that monolingual children with SLI tend to narrow the gap for production but do not exactly close it (Rice, 2004), and in our study the L2-TD and L2-SLI children did not differ significantly for the production probes. One reason for this discrepancy could be sampling error due to the small number of participants in our study. Another reason could be that L2 children with TD this age are not as stable in their accuracy with morphology as monolinguals (Paradis et al., 2016), and because they are less stable, their production of morphology might overlap more with their L2 peers with SLI. Further on this point, it is worth asking why both groups of children displayed relatively lower accuracy for the irregular past tense probe compared to the other probes. The less productive nature of irregular morphology makes it more difficult to acquire (e.g., Lieven \& Tomasello, 2008). Perhaps this underlies the overall lower accuracy with these verbs, as well as the L2-TD and L2-SLI differences in accuracy. L2 children with SLI have fewer overregularization errors with irregular past tense verbs than their TD peers at earlier stages of L2 acquisition, indicating limitations in morphological productivity (Blom \& Paradis, 2013; Jacobson \& Schwartz, 2005).

Taken together, the parallel profile between monolingual TD and SLI and L2-TD and L2-SLI over time with tense morphology and the absence of monolingualL2 differences for SLI at this age mean that this study found no support for the $\mathrm{CEH}$.

\section{Implications for the role of age/maturation and input in acquisition with SLI}

As mentioned above, monolingual children with SLI have an internal, languagelearning deficit that underlies their protracted language development, and research 
to date suggests that deficits in verbal memory and information processing systems are good candidates for the locus of their impairment (Leonard, 2014; Leonard et al., 2007). Leonard et al. (2007) note that the connection between processing deficits and morphological learning has to do with uptake: children with SLI need longer exposure time to learn because their processing deficits make uptake more difficult than in unaffected children. Research by Rice et al. indicates that over time, children with SLI can narrow the gap with their TD peers in production (Rice, 2004; Rice et al., 1998). This outcome could occur because (a) children with SLI simply need all this extra time to get sufficient uptake, or (b) their internal languagelearning deficit improves somewhat over time and/or compensatory mechanisms develop. Option (a) refers to external factors like exposure time, and option (b) refers to internal factors co-indexed with age. In monolingual children with SLI, age and exposure cannot be easily separated: a 6-year-old child has had 6 years of exposure to English. In contrast, age and exposure time can be separated in L2 children where a 10-year-old can have 6 years of exposure to English. Therefore, this separation permits the investigation of whether option (a) or option (b) is the most likely explanation for the developmental trajectories with morphological acquisition in children with SLI.

Blom and Paradis (2015) found that factors predicting individual differences in tense acquisition were different for L2 children with TD and with SLI. For L2 children with TD, longer exposure time to English, older age of L2 acquisition, and having a L1 with grammatical tense increased their accuracy with tense inflection. For the children with SLI, only older age of acquisition predicted higher accuracy with tense. In the present study, we found that L2 children with SLI outperformed younger monolingual children with SLI even though the two groups had identical amounts of exposure to English. The only difference was that the monolinguals had this exposure when they were younger. If children with SLI simply needed more time to achieve sufficient uptake to acquire morphology, we would not have found this result. Therefore, maturation might play an important role in the language learning capacities of children with SLI in that their uptake from the input might improve as they grow older (option [b]; cf. Rice, 2004; Rice et al., 2009). The data in this study do not provide evidence for what the nature of the internal language learning deficit in SLI could be. In other words, this study does not necessarily support verbal memory or information processing as candidates for the locus of impairment as we did not include measures of these mechanisms. Nevertheless, the data in this study do suggest that bilinguals might provide special insights into the nature of acquisition with SLI that could inform future research.

\section{Limitations and conclusions}

A major limitation of the present study is its small sample size. We included very closely matched groups of L2-TD and L2-SLI children in a longitudinal design, and our statistical techniques meant we modeled thousands of data points; therefore, we are confident in our understanding of these children's acquisition patterns. However, this does not change the fact that this study only included 14 children, and monolingual data were taken from a norming sample rather than gathered directly. It is important to point out that the studies by Verhoeven et al. 
had large-scale samples, including monolinguals and bilinguals, and moreover found evidence to support the CEH (Verhoeven, Steenge, \& van Balkom, 2011; Verhoeven, Steenge, van Weerdenburg, et al., 2011). Reasons other than sample size could explain the conflicting findings regarding the CEH between this study and the research by Verhoeven et al. For example, there could be differences in the severity of the clinical populations due to different assessment protocols in the Netherlands and in Canada. There could also be differences in the sociocultural context surrounding support for bilingualism in the two countries that could play a role in outcomes for bilingual children with SLI (cf. Smithson, Paradis, \& Nicoladis, 2014). In sum, this study is a first step toward testing the validity of the CEH with older L2 children with SLI, and more studies should follow.

Limitations aside, we draw the following conclusions from this study: the profile of tense acquisition in English speakers with SLI appears to be the same whether English is a child's L1 or L2, from the early stages until the end of elementary school (taking the present study together with studies by Blom and Paradis, 2013, 2015). The CEH is not supported in these data because the L2 children with SLI clearly showed a capacity for dual language learning. The L2 children with SLI not only were able to achieve similar levels of ability with tense morphology as monolinguals with SLI but also were able to achieve them with less input, suggesting an important role of maturation in shaping the language learning capacities of children with SLI.

\section{ACKNOWLEDGEMENTS}

We thank the families and children for their patience and cooperation in participating in a 3-year longitudinal study and Katryna Lysay, Yasemin Tulpar, Emily Yiu, and Tatianna Zdorenko for assistance with data collection and analyses. We are grateful for the funding for this research by the Social Sciences and Humanities Research Council of Canada (Standard Research Grant 410-2010-0123 to J.P.).

\section{REFERENCES}

Bates, D., Maechler, M., Bolker, B., \& Walker, S. (2013). lme4: Linear mixed-effects models using Eigen and S4. R package version 1.0-5. Retrieved from http://CRAN.R-project.org/package=lme4

Bedore, L., \& Leonard, L. (1998). Specific language impairment and grammatical morphology: A discriminant function analysis. Journal of Speech, Language and Hearing Research, 41, 11851192.

Blom, E., \& Paradis, J. (2013). Past tense production by English second language learners with and without impairment. Journal of Speech, Language and Hearing Research, 56, 1-14.

Blom, E., \& Paradis, J. (2015). Sources of individual differences in the acquisition of tense inflection by English second language learners with and without specific language impairment. Applied Psycholinguistics, 36, 953-976.

Blom, E., Paradis, J., \& Sorenson Duncan, T. (2012). Effects of input properties, vocabulary size and L1 on the development of third person singular $-s$ in child L2 English. Language Learning, 62, 965-994.

Brown, L., Sherbenou, R., \& Johnsen, S. (1997). Test of Nonverbal Intelligence (3rd ed). Austin, TX: Pro-Ed.

Chatterjee, C., \& Hadi, A. S. (2006). Regression analysis by example. Hoboken, NJ: Wiley. 
Chondrogianni, V., \& Marinis, T. (2011). Differential effects of internal and external factors on the development of vocabulary, tense morphology and morpho-syntax in successive bilingual children. Linguistic Approaches to Bilingualism, 1, 318-342.

Conti-Ramsden, G., Botting, N., \& Faragher, B. (2001). Psycholinguistic markers for specific language impairment. Journal of Child Psychology and Psychiatry, 42, 741-748.

Crutchley, A., Botting, N., \& Conti-Ramsden, G. (1997). Bilingualism and specific language impairment in children attending language units. European Journal of Disorders of Communication, $32,267-276$.

Ebert, K. D., Pham, G., \& Kohnert, K. (2014). Lexical profiles of bilingual children with primary language impairment. Bilingualism: Language and Cognition. Advance online publication. doi:10.1017/S1366728913000825

Grüter, T., \& Paradis, J. (2014). Input and experience in bilingual development. Amsterdam: Benjamins.

Gutiérrez-Clellen, V., Simon-Cereijido, G., \& Wagner, C. (2008). Bilingual children with language impairment: A comparison with monolinguals and second language learners. Applied Psycholinguistics, 29, 3-19.

Jacobson, P. (2012). The effects of language impairment on the use of direct object pronouns and verb inflections in heritage Spanish speakers: A look at attrition, incomplete acquisition and maintenance. Bilingualism: Language and Cognition, 15, 22-38.

Jacobson, P., \& Livert, D. (2010). English past tense use as a clinical marker in older bilingual children with language impairment. Clinical Linguistics and Phonetics, 24, 101-121.

Jacobson, P., \& Schwartz, R. (2005). English past tense use in bilingual children with language impairment. American Journal of Speech-Language Pathology, 14, 313-323.

Jia, G., \& Fuse, A. (2007). Acquisition of English grammatical morphology by native Mandarin speaking children and adolescents. Journal of Speech, Language and Hearing Research, 50, 1280-1299.

Jordaan, H., Shaw-Ridley, G., Serfontein, J., Orelowitz, K., \& Monaghan, N. (2001). Cognitive and linguistic profiles of specific language impairment and semantic-pragmatic disorder in bilinguals. Folia Phoniatrica et Logopaedica, 53, 153-165.

Laloi, A. (2015). Language and executive functioning in the context of specific language impairment and bilingualism (Unpublished doctoral dissertation, University of Amsterdam).

Leonard, L. (2014). Children with specific language impairment (2nd ed.). Cambridge, MA: MIT Press.

Leonard, L., Ellis Weismer, S., Miller, C. A., Francis, D., Tomblin, B., \& Kail, R. (2007). Speed of processing, working memory, and language impairment in children. Journal of Speech, Language, and Hearing Research, 50, 408-428.

Lieven, E., \& Tomasello, M. (2008). Children's first language acquisition from a usage-based perspective. In P. Robinson \& N. Ellis (Eds.), Handbook of cognitive linguistics and second language acquisition (pp. 168-196). New York: Routledge.

Marchman, V. A., Wulfeck, B., \& Ellis Weismer, S. (1999). Morphological productivity in children with normal language and SLI: A study of the English past tense. Journal of Speech, Language, and Hearing Research, 42, 206-219.

Marinis, T., \& Chondrogianni, V. (2010). Production of tense marking in successive bilingual children: When do they converge with their monolingual peers? International Journal of SpeechLanguage Pathology, 12, 19-28.

Miller, C., Kail, R., Leonard, L., \& Tomblin, B. (2001). Speed of processing in children with specific language impairment. Journal of Speech, Language, and Hearing Research, 44, 416433.

Montgomery, J., \& Windsor, J. (2007). Examining the language performances of children with and without specific language impairment: Contributions of phonological short-term memory and speed of processing. Journal of Speech, Language, and Hearing Research, 50, 778797. 
Morgan, G. P., Restrepo, A., \& Auza, A. (2013). Comparison of Spanish morphology in monolingual and Spanish-English bilingual children with and without language impairment. Bilingualism: Language and Cognition, 16, 578-596.

Oetting, J., \& Hadley, P. (2009). Morphosyntax in child language disorders. In R. Schwartz (Ed.), Handbook of child language disorders (pp. 341-364). New York: Psychology Press.

Orgassa, A. (2009). Specific language impairment in a bilingual context: The acquisition of Dutch inflection by Turkish-Dutch learners (Unpublished doctoral dissertation, University of Amsterdam).

Orgassa, A., \& Weerman, F. (2008). Dutch gender in specific language impairment and second language acquisition. Second Language Research, 24, 333-364.

Paradis, J. (2008). Tense as a clinical marker in English L2 acquisition with language delay/impairment. In E. Gavruseva \& B. Haznedar (Eds.), Current trends in child second language acquisition: A generative perspective (pp. 337-356). Amsterdam: Benjamins.

Paradis, J. (2010a). The interface between bilingual development and specific language impairment. Keynote article for Special Issue with peer commentaries. Applied Psycholinguistics, 31, 3-28.

Paradis, J. (2010b). The interface between bilingual development and specific language impairment: Response to commentaries. Applied Psycholinguistics, 31, 119-136.

Paradis, J. (2011). Individual differences in child English second language acquisition: Comparing child-internal and child-external factors. Linguistic Approaches to Bilingualism, 1, 213237.

Paradis, J., \& Blom, E. (2016). Do early successive bilinguals show the English L2 pattern of precocious BE acquisition? Bilingualism: Language and Cognition, 19, 630-635.

Paradis, J., Crago, M., \& Genesee, F. (2005-2006). Domain-specific versus domain-general theories of the deficit in SLI: Object pronoun acquisition by French-English bilingual children. Language Acquisition, 13, 33-62.

Paradis, J., Crago, M., Genesee, F., \& Rice, M. (2003). Bilingual children with specific language impairment: How do they compare with their monolingual peers? Journal of Speech, Language and Hearing Research, 46, 1-15.

Paradis, J., Emmerzael, K., \& Sorenson Duncan, T. (2010). Assessment of English language learners: Using parent report on first language development. Journal of Communication Disorders, 43, 474-497.

Paradis, J., \& Jia, R. (2016). Bilingual children's long-term outcomes in English as a second language: Language environment factors predict individual differences in catching up to monolinguals. Developmental Science. Advance online publication. doi:10.1111/desc.12433

Paradis, J., Rice, M., Crago, M., \& Marquis, J. (2008). The acquisition of tense in English: Distinguishing child second language from first language and specific language impairment. Applied Psycholinguistics, 29, 1-34.

Paradis, J., Schneider, P., \& Sorenson Duncan, T. (2013). Discriminating children with language impairment among English language learners from diverse first language backgrounds. Journal of Speech, Language and Hearing Research, 56, 971-981.

Paradis, J., Tulpar, Y., \& Arppe, A. (2016). Chinese L1 children's English L2 verb morphology over time: Individual variation in long-term outcomes. Journal of Child Language, 43, 553580 .

Peets, K., \& Bialystok, E. (2010). An integrated approach to the study of specific language impairment and bilingualism. Applied Psycholinguistics, 31, 315-319.

R Core Team. (2013). R: A language and environment for statistical computing. Vienna: R Foundation for Statistical Computing. Retrieved from http://www.R-project.org/

Rice, M. L. (2003). A unified model of specific and general language delay: Grammatical tense as a clinical marker of unexpected variation. In Y. Levy \& Schaeffer (Eds.), Language competence across populations: Towards a definition of specific language impairment (pp. 63-94). Mahwah, NJ: Erlbaum. 
Rice, M. L. (2004). Growth models of developmental language disorders. In M. L. Rice \& S. Warren (Eds.), Developmental language disorders: From phenotypes to etiologies (pp. 207-240). Mahwah, NJ: Erlbaum.

Rice, M. L. (2010). Evaluating maturational parallels in second language children and children with specific language impairment. Applied Psycholinguistics, 31, 320-327.

Rice, M. L., \& Blossom, M. (2012). What do children with specific language impairment do with multiple forms of DO? Journal of Speech, Language and Hearing Research, 56, 222-235.

Rice, M. L., \& Wexler, K. (1996). Toward tense as a clinical marker of specific language impairment. Journal of Speech, Language, and Hearing Research, 39, 1236-1257.

Rice, M. L., \& Wexler, K. (2001). Test of Early Grammatical Impairment. New York: Psychological Corporation.

Rice, M. L., Wexler, K., \& Hershberger, S. (1998). Tense over time: The longitudinal course of tense acquisition in children with specific language impairment. Journal of Speech, Language, and Hearing Research, 41, 1412-1431.

Rice, M. L., Wexler, K., Marquis, J., \& Hershberger, S. (2000). Acquisition of irregular past tense by children with specific language impairment. Journal of Speech, Language and Hearing Research, 43, 1126-1145.

Rice, M. L., Wexler, K., \& Redmond, S. (1999). Grammaticality judgments of an extended optional infinitive grammar: Evidence from English-speaking children with SLI. Journal of Speech, Language and Hearing Research, 42, 943-961.

Rothweiler, M. (2010). The potential of studying SLI in bilinguals for linguistic research on SLI in monolinguals. Applied Psycholinguistics, 31, 102-106.

Rothweiler, M., Chilla, S., \& Clahsen, H. (2012). Subject verb agreement in specific language impairment: A study of monolingual and bilingual German-speaking children. Bilingualism: Language and Cognition, 15, 39-57.

Smithson, L., Paradis, J., \& Nicoladis, E. (2014). Bilingualism and vocabulary achievement: Could sociocultural context make a difference? Bilingualism: Language and Cognition, 17, 810-821.

Steenge, J. (2006). Bilingual children with specific language impairment: Additionally disadvantaged? (Doctoral dissertation, Radbound University).

Tomblin, J. B., Zhang, X., Buckwalter, P., \& O’Brien, M. (2003). The stability of primary language disorder: Four years after kindergarten diagnosis. Journal of Speech, Language and Hearing Research, 46, 1283-1296.

Verhoeven, L., Steenge, J., \& van Balkom, H. (2011). Verb morphology as a clinical marker of specific language impairment: Evidence form first and second language learners. Research in Developmental Disabilities, 32, 1186-1193.

Verhoeven, L., Steenge, J., van Weerdenburg, M., \& van Balkom, H. (2011). Assessment of second language proficiency in bilingual children with specific language impairment: A clinical perspective. Research in Developmental Disabilities, 32, 1798-1807. 